\title{
DIFFERENTIATION OF HUMAN OLFACTORY BULB NEURAL STEM CELLS INTO OLIGODENDROCYTES
}

\author{
Shouman, Z.A., Abd-Elmaksoud, A., Lashen, S. and Hany E. Marei \\ Department of Cytology and Histology, Faculty of veterinary medicine, Mansoura University, Egypt, and Biomedical \\ Research Center, Qatar University, Doha, Qatar
}

\begin{abstract}
Human olfactory bulb neural stem cells (OBNSCS) are multipotent cells that are capable of differentiation into neurons, astrocytes, and oligodendrocytes. In the present study, we investigated the ability of human OBNSCS to differentiate into oligodendrocytes using RT-PCR and immunocytochemistry. In the presence of fetal calf serum, all-trans retinoic acid (RA), triiodothyronine (T3), and cyclic adenosine monophosphate (cAMP), OBNSCS were differentiated into oligodendrocytes precursors as evidenced by induction and repression of oligodendrocytes chondroitin sulphate proteoglycan (NG2) and nestin genes, respectively. These finding were confirmed at the protein level using fluorescent immunocytochemistry (FICC) according to standard protocol. Taken together, the present study highlighted the ability of OBNSC to differentiate into oligodendrocytes, a finding that indicates their possible use as a promising candidate for cell-based therapy for neurodegenerative and traumatic diseases associated with myelin impairments.

Abbreviations: Human olfactory bulb neural stem cells (OBNSCs), retinoic acid (RA), triiodothyronine (T3), cyclic adenosine monophosphate (cAMP), pro-oligodendrocytes chondroitin sulphate proteoglycan (NG2), immunocytochemistry (FICC).
\end{abstract}

\section{INTRODUCTION}

Oligodendrocytes are the glia in charge of myelin formation. Its tiny size denies the scale of myelin production that can ensheath lots of axons in many layers. But until 1950, several studies thought that myelin sheath produced from axons not glia (Geren and Raskind, 1953; Geren, 1954).

Oligodendrocyte precursor cells (OPCs) transplantation may be a promising therapeutic strategy for diseases affecting myelin. Clinical attention was given to the ability of human neural stem cells (NSCs) to generate OPCs for therapeutic use, since great numbers of pure OPCs are required to treat these diseases. Till today, information are insufficient around NSCs differentiation to OPCs, but Caiying et al. (2014) successfully differentiated human fetal NSCs to OPCs using a mixture of basic fibroblast growth factor (bFGF), plateletderived growth factor (PDGF), and neurotrophic factor-3 (NT-3).

Other studies (Glaser et al., 2005; Izrael et al., 2007; Kang et al., 2007) have used media comprising a cocktail of growth factors such as sonic hedgehog (Shh), PDGF, FGF2, insulin like growth factor 1 (IGF1), and NT-3 or bone 
morphogenic protein antagonists for the differentiation of NSC into OPCs. An alternative method is the oligodendrocyte transcription genes transfection. Clear nominees are the oligodendrocytes lineage transcription genes (Olig1). Transfection of mouse embryonic NSCs with Olig1 stimulated OPCs production; though, these OPCs seem incapable to employee manufacturing transcription factors such as protein $\mathrm{Nkx}-2.2$ (Balasubramaniyan et al., 2004).

Olig2 seems to be more effective in induction of OPCS from NSCs. Transfection of mouse embryonic NSCs with Olig2, induced their differentiation into OPCs with expression of Nkx2.2 and complete growth (Copray et al., 2006). In addition, adult mouse NSCs could prompt OPC induction when Olig2 is expressed (Hack et al., 2005). Olig2 transfected NSCs generated a higher number of oligodendrocytes as compared to neuronal or other glial cells type (Du et al., 2006). Additionally, OPC generation from NSC needs an incorporated interaction between the transcription genes Olig2, Sox9/10, Nkx6.1/6.2, Mash1 and YY1 (Liu et al., 2007).

This study aimed to isolate and culture the human OBNSCs, and to study their possible ability to differentiate into oligodendrocytes using Rt-PCR and FICC.

\section{MATERIALS AND METHODS}

\section{Isolation and culturing of human olfactory bulb NSCs}

After obtaining the IRB approval from the ethical committee at Catholic University, Rome, Italy, samples ( $n=5)$ from the olfactory bulbs (OBs) of human patients (39-45 years old) that were undergoing craniotomy for resection of brain tumours were collected. .

Directly after collection, the OBs were digested with Papain $0.1 \%$ (Sigma-Aldrich) for
$30 \mathrm{~min}$ at $37{ }^{\circ} \mathrm{C}$. Cells were cultured in Dulbecco's modified eagle's medium F-12 (DMEM-F12) (1:1) (Invitrogen) supplemented with human recombinant epidermal growth factor $(20 \mathrm{ng} / \mathrm{ml}$; PeproTech $)$, human recombinant basic fibroblast growth factor (10 $\mathrm{ng} / \mathrm{ml}$; PeproTech), and leukemia inhibitory factor $(20 \mathrm{ng} / \mathrm{ml}$; Immunological Sciences). Following one week of culture, cellular clusters, neurospheres, were formed. Half of the media was changed every other day, and following $80 \%$ confluency, the culture plates were split using Accutase (Invitrogen) at $37^{\circ} \mathrm{C}$ for $4 \mathrm{~min}$. Following splitting, the cells viability and count were done using hemocytometer and trypan blue exclusion tests. Differentiation was preformed after 5 days of culturing six-welled plates with removal of growth factors and addition of fetal calf serum $1 \%$ (Hyclone), cyclic adenosine monophosphate (cAMP-Sigma-Aldrich) $50 \mathrm{mM}$, all-trans retinoic acid $5 \mathrm{mM}($ Sigma Aldrich), and triiodothyronine (T3) $30 \mathrm{nM}$ (Sigma Aldrich) (Pagano et al., 2000).

\section{Immunocytochemistry}

OBNSCs and differentiated cells were fixed on coverslips, poly-L-lysine coated, with 4\% paraformaldehyde in phosphate-buffered saline (PBS), $\mathrm{pH} 7.4$ at room temperature for 5 min, followed by incubation with PBS and $0.5 \%$ Triton X-100 at room temperature for 10 min. Once non-specific reaction was blocked by PBS containing 10\% goat serum, the cells were incubated with primary antibodies diluted in $1 \%$ bovine serum albumin, working concentrations range from $5-20 \mu \mathrm{g} / \mathrm{mL}$. We used antibodies against nestin after proliferation, and NG2 after differentiation. Then, they were incubated at room temperature for $30 \mathrm{~min}$ with a mixture of Tetramethyl rhodamine isothiocyanate (TRITC) affinity purified goat anti-rabbit and fluorescein isothiocyanate (FITC) affinity purified donkey anti-mouse) (Invitrogen) diluted in 1\% BSA, 
dilutions range from $1-2 \mu \mathrm{g} / \mu \mathrm{L}$. After several washes and mounting, the cells were examined using Olympus BX51 universal fluorescent microscope (Marchenko and Flanagan, 2007).

\section{Reverse transcription-PCR analysis}

Total RNA were extracted during proliferated and after differentiated of OBNSCs into oligodendrocytes using Trizol and RNeasy mini kit (Qiagen, USA). cDNAs were generated using QuantiTect Reverse Transcription kit (Qiagen, USA). Quantitative Real Time Reverse Transcriptase PCR (RT-qPCR) was conducted using 2X Maxima SYBR Green/ROX qPCR Master Mix (Thermo scientific, USA). Nine ng of total RNA was used in $50 \mu 1$ mix containing $3 \mu \mathrm{l}$ of cDNA template and $0.1 \mu \mathrm{M}$ of the particular primers pair. Cycle considerations were $15 \mathrm{sec}$ at $95^{\circ} \mathrm{C}, 30 \mathrm{sec}$ at $57-60^{\circ} \mathrm{C}$, and $30 \mathrm{sec}$ at $72^{\circ} \mathrm{C}$ for 45 cycles. The sequences of oligonucleotides used for RT-qPCR were described in Table 1:

\section{RESULTS}

Under phase contrast microscope, the undifferentiated OBNSC were small spherical cells with spherical nuclei, and bright appearance. On day two of culture, some OBNSCs appeared to have short cytoplasmic processes (Fig. 1) as a first evidence for their differentiation into oligodendrocytes. With continued culture, the cytoplasmic processes increased in length, and by the $5^{\text {th }}$ day, there was an apparent decrease in the number of differentiated cells with pronounced branching of their cytoplasmic processes (Fig. 2).

\section{Immunocytochemical assessment}

The morphological features revealed during the differentiation of OBNSCS into oligodendrocytes were confirmed at the immunohistochemical levels using two of the most important markers for undifferentiated and oligodendrocytic differentiation state; nestin and NG2, respectively. During the proliferation period, most of the OBNSCs showed a positive immunoreactivity for nestin indicating their undifferentiated nature (Fig. 3), whereas following five days in the previously described oligodendrocytes differentiation media, there was a considerable decrease in the number of nestin positive cells which was associated with a concomitant increase in the number of NG2 immunoreactive cells (Fig. 4).

\section{Real-time quantitative PCR analysis}

Next, we studies the gene expression profile during proliferation of OBNSCs, and following their differentiation into oligodendrocytes. Again, we have selected to study the two most important undifferentiation, and oligodendrocytes markers; nestin and NG2, respectively. We have used the relative expression of nestin and NG2 genes relative to GAPDH housekeeping gene. A significant $(\mathrm{P} \leq 0.05)$ upregulation of the relative expression of NG2 was revealed in differentiated oligodendrocytes as compared to proliferating undifferentiated OBNSCs (Table 2, Fig. 5)

Table 1: primers sequence used in RT-PCR for nestin and NG2 genes.

\begin{tabular}{|c|c|c|}
\hline Gene name & Forward sequence & Backward sequence \\
\hline Nestin & GAAACAGCCATAGAGGGCAAA & TGGTTTTCCAGAGTCTTCAGTGA \\
\hline NG2 & CACGGCTCTGACCGACATAG & CCCAGCCCTCTACGACAGT \\
\hline
\end{tabular}



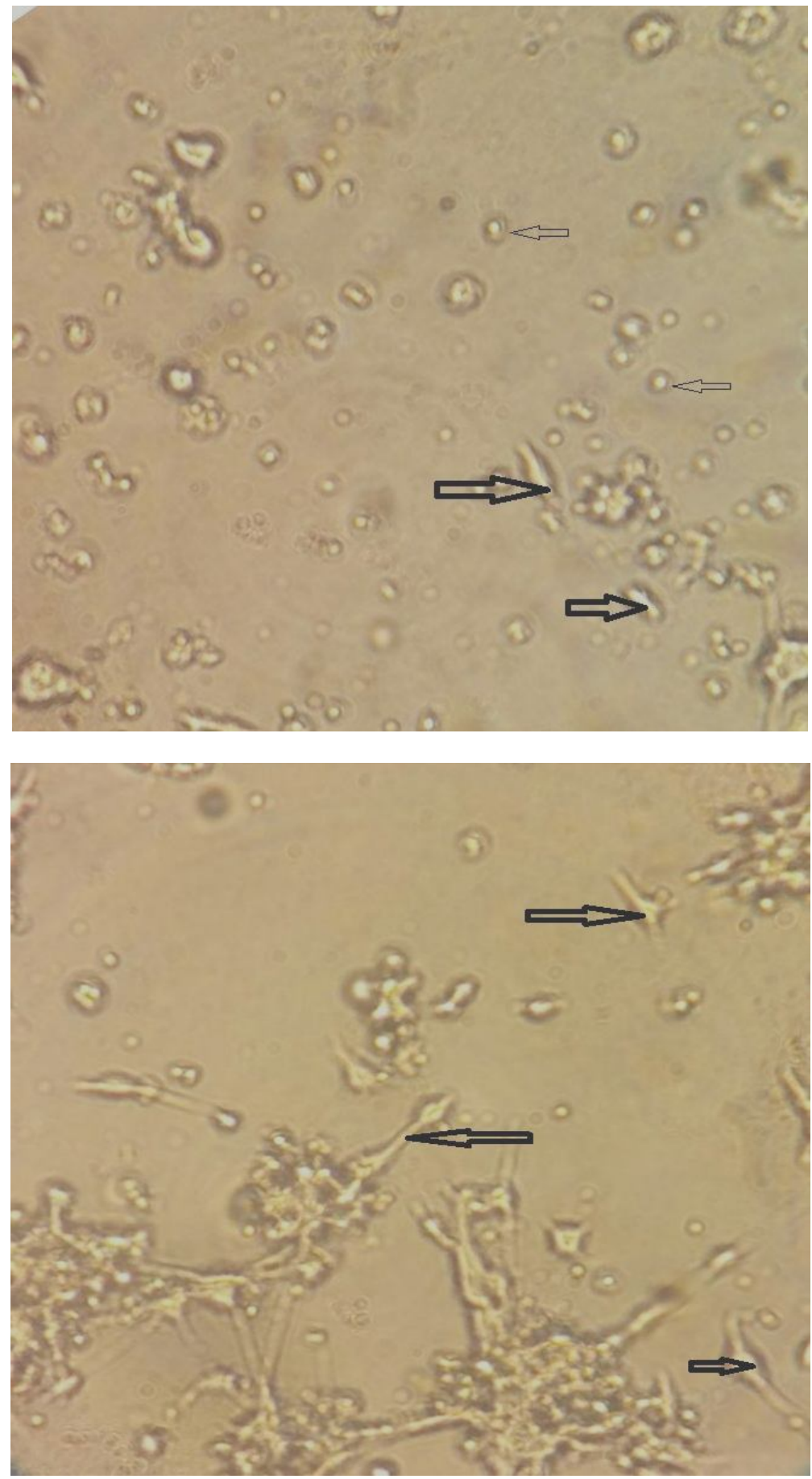

Figure 1: Phase contrast microscopic image after one day incubation in oligodendrocyte specific differentiation medium showing the presence of two types of OBNSCs morphology: undifferentiated OBNSCs with no changes in their spherical morphology (thin arrows), and early differentiated cells with short cytoplasmic processes (thick arrows). 

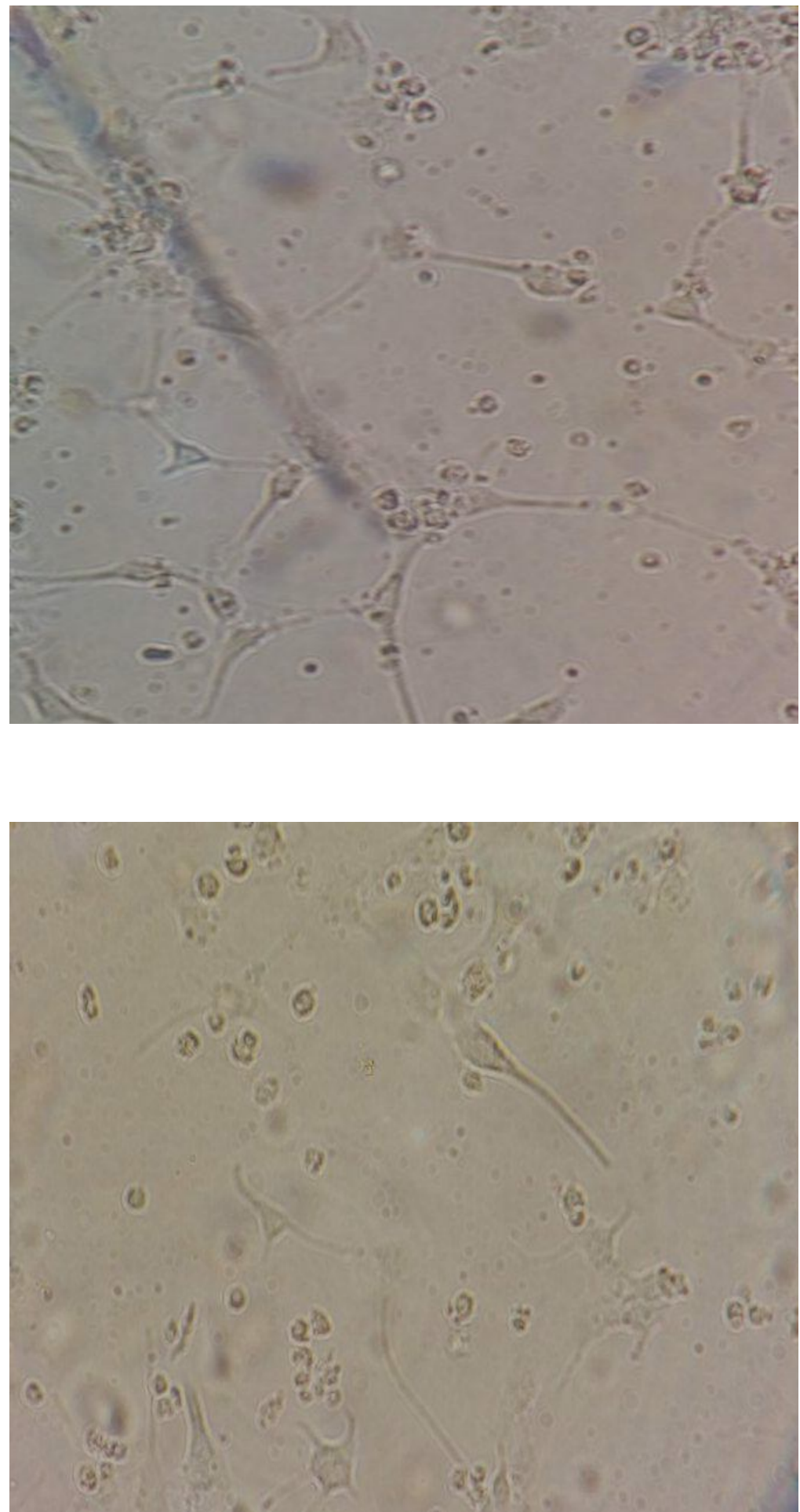

Figure 2: Phase contrast images for differentiated oligodendrocytes five days post incubation in specific oligodendrocytes differentiation media showing extensively branched oligodendrocytes-like cells, with a concomitant decrease in the number of undifferentiated OBNSCs. 


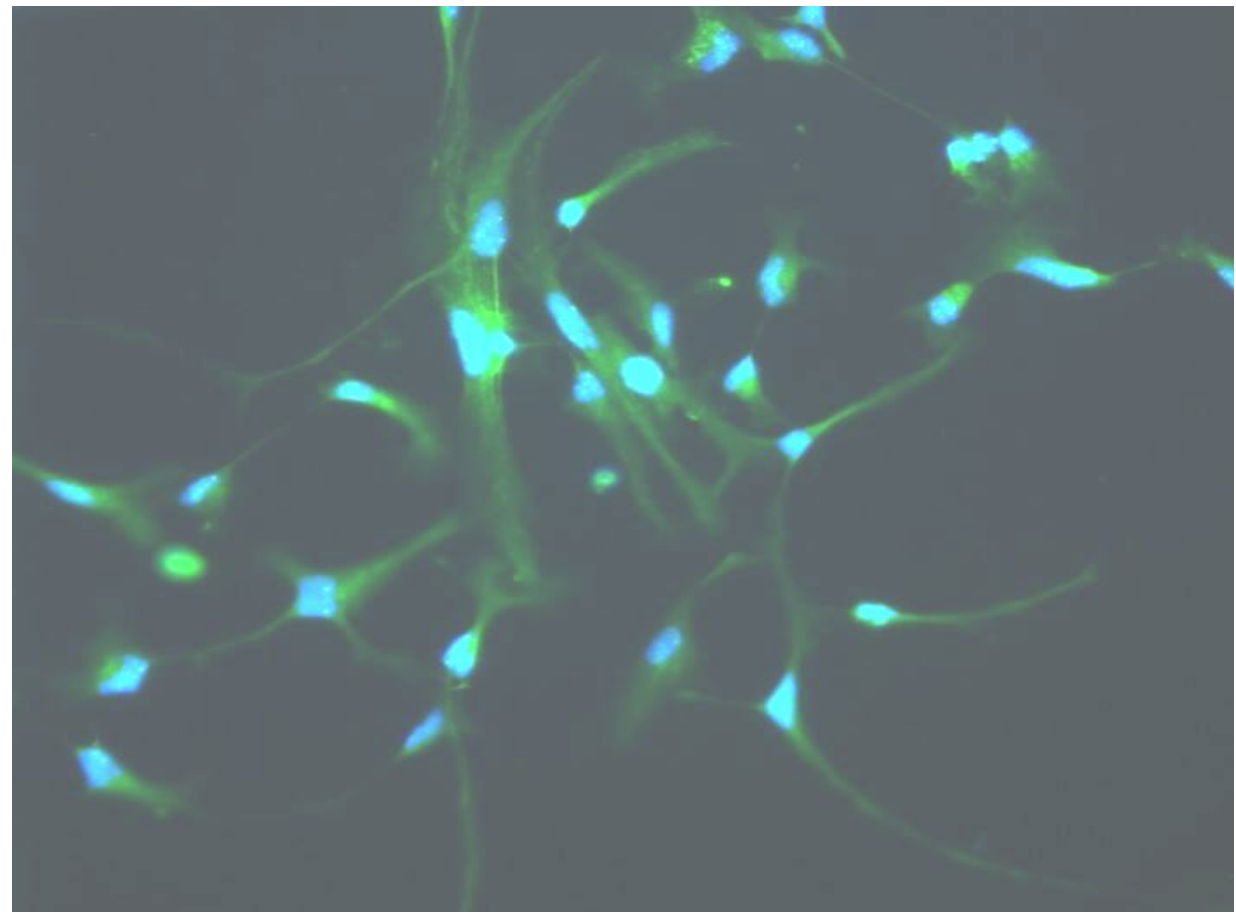

Figure 3: Fluorescent image (20X) for undifferentiated OBNSCs showing positive reactivity (green) for Nestin, and blue Hoechst-stained nuclei.

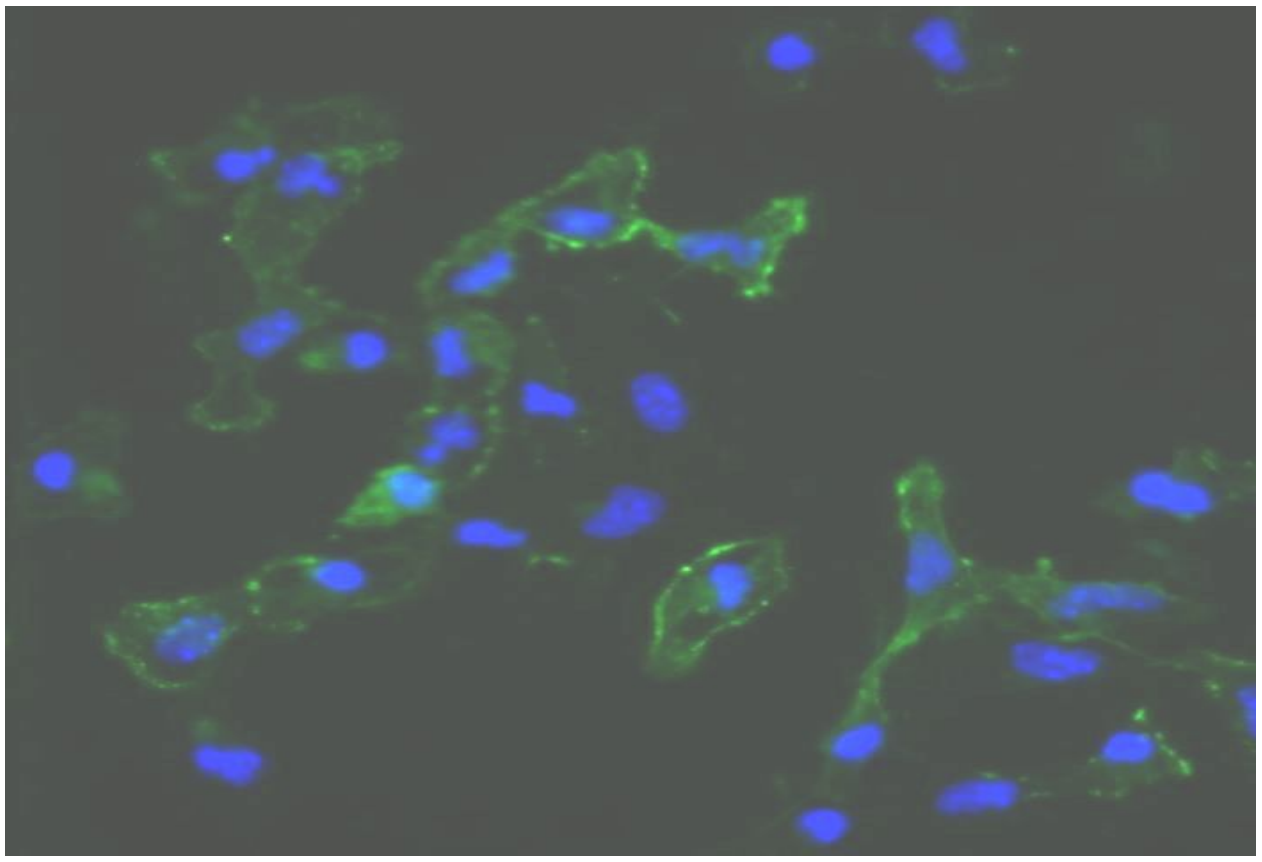

Figure 4: Fluorescent image (40X) showing differentiation of OBNSCs into NG2 (green) positive branched cells, with blue Hoechst-stained nuclei. 
Table 2: Relative expression of NG2/ GAPDH housekeeping genes during proliferation and differentiation state depicting a significant $(\mathrm{P} \leq 0.05)$ fold increase between undifferentiated OBNSCs and differentiated oligodendrocytes.

\begin{tabular}{|l|c|c|c|}
\hline Gene & Group & Fold change & SE \\
\hline \multirow{2}{*}{ NG2 } & Proliferation & 1.00 & 0.08 \\
\cline { 2 - 4 } & Differentiation & 3.92 & 0.12 \\
\hline
\end{tabular}

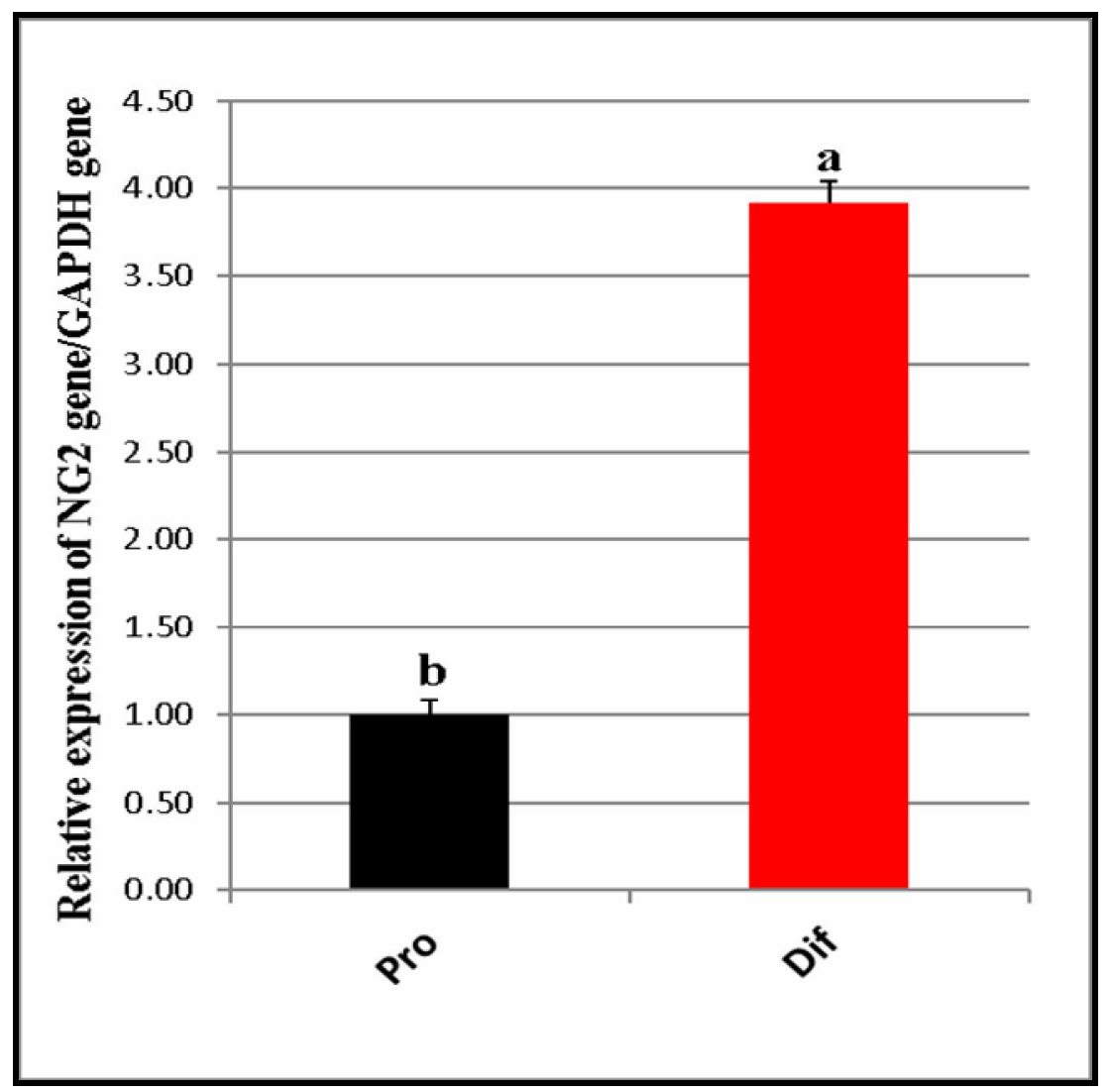

Figure 5: Graphical presentations for real-time quantitative PCR (qRT-PCR) analysis of the expression of NG2 gene during proliferation (Pro) and differentiation (Dif) state showing a significant upregulation of NG2 in differentiated oligodendrocytes as compared to undifferentiated OBNSCs.

Next, we studies the expression level of undifferentiated markers during the differentiation of OBNSCs into oligodendrocytes relative to GAPDH housekeeping gene. We recorded a significant $(\mathrm{P} \leq 0.05)$ downregulation in the expression level of nestin gene, a marker for undifferentiated neural stem cells in differentiated cells as compared to proliferated OBNSCs (Table 3, Fig.6). 
Table 3: Relative expression of Nestin gene/ GAPDH housekeeping genes during proliferation and differentiation of OBNSCs into oligodendrocytes showing a significant $(\mathrm{P} \leq 0.05)$ increase in the expression level of nestin during proliferation status as compared to differentiation one.

\begin{tabular}{|l|c|c|}
\hline & Fold change & SE \\
\hline Proliferation & 1.00 & 0.06 \\
\hline Differentiation & 0.19 & 0.04 \\
\hline
\end{tabular}

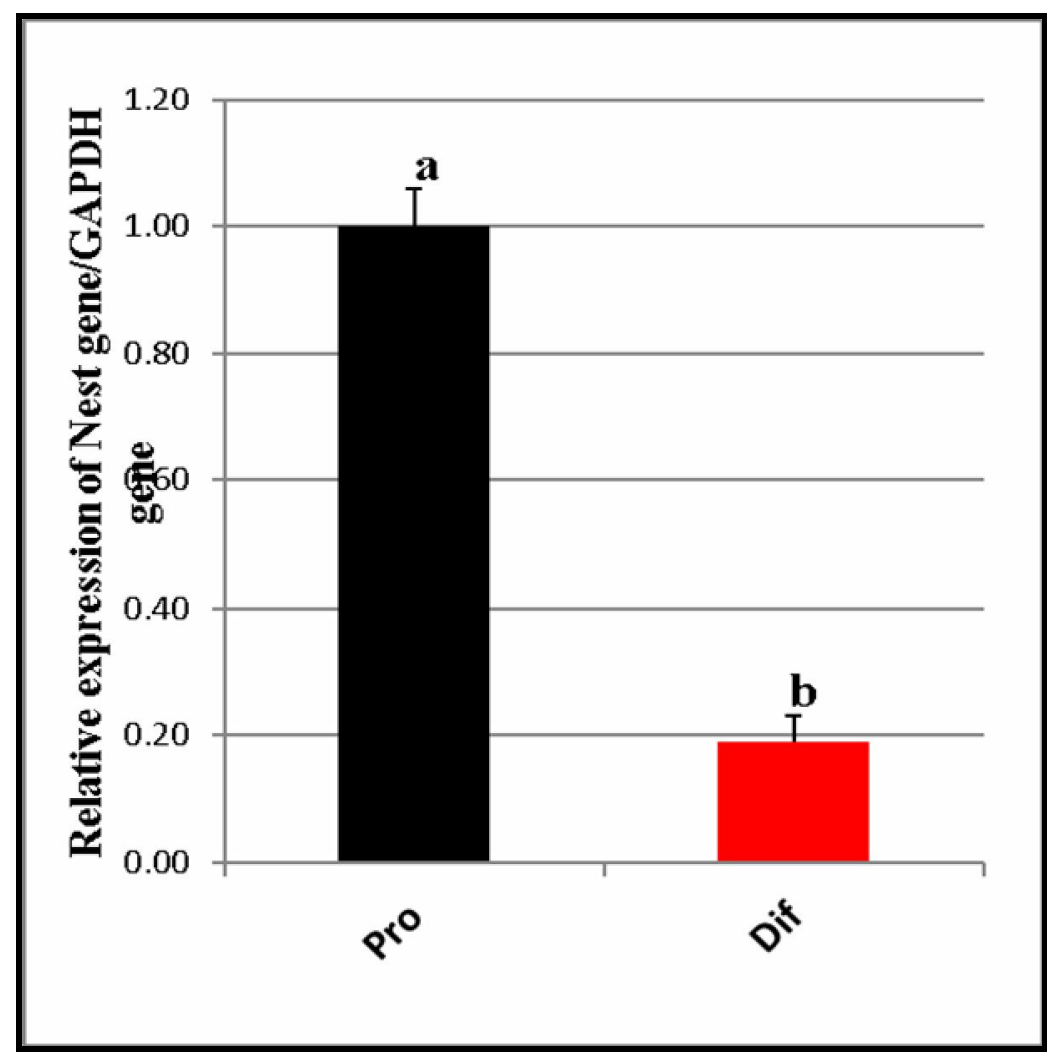

Figure 6: Graphical presentations for real-time quantitative PCR (qRT-PCR) analysis of the expression of nestin gene during proliferation (Pro) and differentiation (Dif) state showing a significant upregulation of nestin in undifferentiated OBNScs as compared to differentiated oligodendrocytes. 


\section{DISCUSSION}

The present study was designed to investigate the ability of human OBNSCs to differentiate into oligodendrocytes. Trials for provision of a pure source of oligodendrocytes are crucial for cellular-based therapy for a wide array of traumatic and neurodegenerative diseases associated with myelin impairments. Here, we have succeeded to isolate NSCs from human olfactory bulb, and to differentiate these cells into oligodendrocytes. Despite the invasive nature of the surgical protocol used to collect human OBNSCs, recent discovery about the possible use of non-invasive techniques for the generation of NSCs from autologous induced pluripotent stem cells (iPSCs) from patient somatic (skin) cells would provide a promising therapeutic cellbased strategy for the previously mentioned neurological insults (Lee-Kubli and $\mathrm{Lu}, 2015$ ).

Even after successful generation of NSC from iPSCs, the process of differentiation of NSC into oligodendrocytes still need to be optimized. This gap had prompted us to investigate the molecular mechanism(s) underpinning the differentiation of OBNSC into oligodendrocytes. Sorting of a pure culture of fully differentiated oligodendrocytes using recent cell sorting protocols such as fluorescent activated cell sorting (FACS) based on specific oligodendrocytes markers such as NG2 would provide an ideal source of cells that could be used for cellular therapy of myelin-impairment affections.

In the present study, exposure of human OBNScs for five days into a mitogen-free DMEM:F12 media supplemented with $1 \%$ fetal calf serum, $50 \mathrm{mM}$ cAMP, $5 \mathrm{mM}$ alltrans retinoic acid, and $30 \mathrm{nM} \mathrm{T} 3$ induced OBNSCs to differentiated into branched NG2positive oligodendrocytes. Earlier researches have shown that long-standing culture and spreading out human OPCs after their isolation from CNS require more than one cytokine for example bFGF, T3, PDGF-AA, and NT3 (Ruffini et al., 2004; Cui et al., 2014), and cells are able to be conserved for 1-7 days via the use of $\mathrm{N} 1$ and bFGF (Windrem et al., 2004; Bin et al., 2012).

Other studies demonstrated that differentiation of OPCs from NSCs requires their culture in a mixture of cytokines such as bFGF, PDGF-AA, Shh, NT-3, and T3 (Neri et al., 2010; Monaco et al., 2012). In comparison human embryonic stem cells (hESCs) derived OPCs need more cytokines, demanding techniques, and longer time. This apparently costly, and time consuming techniques was previously reported by many studies (Nistor et al., 2005; Kang et al., 2007; Hu et al., 2009; Sundberg et al., 2010). Moreover, hESCs have a probable tumorigenicity risk (Bjorklund et al., 2002; Isobe et al., 2014; Suzuki et al., 2014). These drawbacks narrow the possible use and efficiency of human embryonic stem cells (hESCs) for generation of OPCs.

Researchers invented a simple and economic method, decreases the fee of the experiment, for the production of OPCs. In the addition of B27, single growth factor, specifically, bFGF, is enough to preserve the development as well as propagation of OPCs (Yabin et al., 2015). Earlier studies have proved that medium containing N1 and bFGF could uphold OPCs for only a short time. In Yabin et al (2015) study, they used B27 as an alternative to N1, and found that OPCs had greater activity in medium having B27 matched to medium having $\mathrm{N} 1$, and their medium impressively improved the growth of OPCs as OPCs proliferated more than 14 times after four passages. B27 has been informed to improve the survival of OPCs, particularly at low density (Svendsen et al., 1995; Yang et al., 2005; Kubota et al., 2013), and bFGF is famous to enhance the propagation of cultivated cells (Gard and Pfeiffer, 1993; Cui et al., 2014). 
In this study, using gene expression profiling and ICC shifting of OBNSCs from media contained bFGF and EGF to a media contained cAMP, T3, and RA resulted differentiation of OBNScs into $\mathrm{NG} 2$ immunoreactive cells. NG2 is a marker for oligodendrocytes precursor cells, this was confirmed using the real-time PCR which demonstrated the upregulation of NG2 genes in differentiated oligodendrocytes as compared to undifferentiated OBNSCs Concomitant with the upregulation of NG2, there we have demonstrated a significant decrease of undifferentiated nestin markers both at the gene and protein expression level using qRTPCR and ICC, respectively. Upregulation of NG2 gene suggested that cells could give oligodendrocytes as all the experimental evidence produced using animal models of demyelinating disease is highly suggestive of $\mathrm{NG} 2+$ cells as the source of new oligodendrocytes and there is no evidence to date that $\mathrm{NG} 2+$ cells that react to demyelination give rise to new astrocyte.

Taken together, the present study clearly indicated the marked ability of human OBNSC to differentiate into oligodendrocytes under the effects of mitogen-free media containing fetal calf serum, cAMP, all-trans retinoic acid, and T3. A finding which is crucial for provision of an effective pure culuture of differentiated oligodendrocytes needed for cellular-based therapy for a long list of myelin-impairment diseases.

\section{CONCLUSION}

Human olfactory bulb neural stem cells can generate oligodendrocytes precursor cells that may transformed into oligodendrocytes if sorted.

\section{REFERENCES}

Balasubramaniyan,V., Timmer,N., Kust,B., Boddeke,E., and Copray,S. (2004): Transient expression of Olig1 initiates the differentiation of neural stem cells into oligodendrocyte progenitor cells. Stem Cells 22, 878-882.

Bin, J.M., Leong, S.Y., Bull, S.J., Antel, J.P., Kennedy, T.E., (2012): Oligodendrocyte precursor cell transplantation into organotypic cerebellar shiverer slices: a model to study myelination and myelin maintenance. PLoS One 7, e41237.

Bjorklund, L.M., Sanchez-Pernaute, R., Chung, S., Andersson, T., Chen, I.Y., McNaught, K.S., Brownell, A.L., Jenkins, B.G., Wahlestedt, C., Kim, K.S., Isacson, O., (2002): Embryonic stem cells develop into functional dopaminergic neurons after transplantation in a Parkinson rat model. Proc. Natl. Acad. Sci. U. S. A. 99, 2344-2349.

Caiying, W., Zuo, L., Yinxiang, Y., Zhaoyan, W., Qian, W., Yabin, L., Qingan, D., (2014): High purity of human oligodendrocyte progenitor cells obtained from neural stem cells: Suitable for clinical application. Journal of Neuroscience Methods 240, 61-66.

Copray,S.,

Balasubramaniyan, $V$., Levenga,J., de,B.J., Liem,R., and Boddeke,E. (2006): Olig2 overexpression induces the in vitro differentiation of neural stem cells into mature oligodendrocytes. Stem Cells 24, 1001-1010.

Cui, Q.L., Fang, J., Kennedy, T.E., Almazan, G., Antel, J.P., (2014): 
Role of p38MAPK in S1P receptormediated differentiation of human oligodendrocyte progenitors. Glia 62, 1361-1375.

Du,Z.W., Li,X.J., Nguyen,G.D., and Zhang,S.C. (2006): Induced expression of Olig2 is sufficient for oligodendrocyte specification but not for motoneuron specification and astrocyte repression. Mol. Cell Neurosci. 33, 371-380.

Gard, A.L., Pfeiffer, S.E., (1993): Glial cell mitogens bFGF and PDGF differentially regulate development of $\mathrm{O} 4+\mathrm{GalC}$ oligodendrocyte progenitors. Dev. Biol. 159, 618-630.

Geren, B.B., (1954): The formation from the schwann cell surface of myelin in the peripheral nerves of chick embryos. Exp Cell Res. 1954 Nov; 7(2):558-62.

Geren, B.B., Raskind, J. (1953): Development of the fine structure of the myelin sheath in sciatic nerves of chick embryos. Proc Natl Acad Sci U S A 39: $880-884$.

Glaser,T., Perez-Bouza,A., Klein,K., and Brustle, O. (2005): Generation of purified oligodendrocyte progenitors from embryonic stem cells. FASEB J. $19,112-114$.

Hack,M.A., Saghatelyan,A., deChevigny,A., Pfeifer,A., shery-Padan,R., Lledo,P.M., and Gotz,M. (2005): Neuronal fate determinants of adult olfactory bulb neurogenesis. Nat. Neurosci. 8, 865-872.

Hu, B.Y., Du, Z.W., Zhang, S.C., (2009): Differentiation of human oligodendrocytes from pluripotent stem cells. Nat. Protoc. 4, 1614-1622.

Isobe, K.I., Cheng, Z., Nishio, N., Suganya, T., Tanaka, Y., Ito, S., (2014): iPSCs, aging and age-related diseases. New Biotechnol. 31, 411-421.

Izrael M, P. Zhang, R. Kaufman, V. Shinder, R. Ella, M. Amit, J. Itskovitz-EIdor, J. Chebath, M. Revel, (2007): Human oligodendrocytes derived from embryonic stem cells: effect of noggin on phenotypic differentiation in vitro and on myelination in vivo, Mol. Cell Neurosci. 34 (3) 310-323.

Kang, S.M., Cho, M.S., Seo, H., Yoon, C.J., Oh, S.K., Choi, Y.M., Kim, D.W., (2007): Efficient induction of oligodendrocytes from human embryonic stem cells. Stem Cells 25, 419-424.

Kubota, K., Seno, T., Konishi, Y., (2013): A low-density culture method of cerebellar granule neurons with paracrine support applicable for the study of neuronal morphogenesis. Brain Res. 1539, 15-23.

Lee-Kubli, C.A. and Lu, P. (2015): Induced pluripotent stem cell-derived neural stem cell therapies for spinal cord injury. Neural Regen Res.10(1): 10-16.

Liu, Z., Hu, X., Cai, J., Liu, B., Peng, X., Wegner, M., and Qiu, M. (2007): Induction of oligodendrocyte differentiation by Olig2 and Sox10: evidence for reciprocal interactions and dosage-dependent mechanisms. Dev. Biol. 302, 683-693.

Marchenko, S. and Flanagan, L., (2007): Immunocytochemistry: Human Neural Stem Cells. J Vis Exp.(7): 267.

Monaco, M.C., Maric, D., Bandeian, A., Leibovitch, E., Yang, W., Major, E.O., (2012): Progenitor-derived oligodendrocyte culture system from human fetal brain. J. Vis. Exp. 20. 
Neri, M., Maderna, C., Ferrari, D., Cavazzin, C., Vescovi, A.L., Gritti, A., (2010): Robust generation of oligodendrocyte progenitors from human neural stem cells and engraftment in experimental demyelination models in mice. PLoS One 5, e10145.

Nistor, G.I., Totoiu, M.O., Haque, N., Carpenter, M.K., Keirstead, H.S., (2005): Human embryonic stem cells differentiate into oligodendrocytes in high purity and myelinate after spinal cord transplantation. Glia 49, 385-396.

Pagano, S.F., Impagnatiello, F., Girelli, M., Cova, L., Grioni, E., Onofri, M., Cavallaro, M., Etteri, S., Vitello, F., Giombini, S., Solero, C.L., Parati, E.A, (2000): Isolation and characterization of neural stem cells from the adult human olfactory bulb. Stem Cells, 18(4):295-300.

Ruffini, F., Arbour, N., Blain, M., Olivier, A., Antel, J.P., (2004): Distinctive properties of human adult brainderived myelin progenitor cells. Am. J. Pathol. 165, 2167-2175.

Sundberg, M., Skottman, H., Suuronen, R., Narkilahti, S., (2010): Production and isolation of $\mathrm{NG} 2+$ oligodendrocyte precursors from human embryonic stem cells in defined serum-free medium. Stem Cell Res. 5, 91-103.
Suzuki, D.E., Nakahata, A.M., Okamoto, O.K., (2014): Knockdown of E2F2 inhibits tumorigenicity, but preserves stemness of human embryonic stem cells. Stem Cells Dev. 23, 1266-1274.

Svendsen, C.N., Fawcett, J.W., Bentlage, C., Dunnett, S.B., (1995): Increased survival of rat EGF-generated CNS precursor cells using B27 supplemented medium. Exp. Brain Res. 102, 407-414.

Windrem, M.S., Nunes, M.C., Rashbaum, W.K., Schwartz, T.H., Goodman, R.A., McKhann 2nd, G., Roy, N.S., Goldman, S.A., (2004): Fetal and adult human oligodendrocyte progenitor cell isolates myelinate the congenitally dysmyelinated brain. Nat. Med. 10, 93-97.

Yabin, L., Yinxiang, Y., Zhaoyan, W., Caiying, W., Qingan, D., Qian, W., Zuo, L., (2015): Isolation and culture of human oligodendrocyte precursor cells from neurospheres. Brain Research Bulletin 118, 17-24.

Yang, Z., Watanabe, M., Nishiyama, A., (2005): Optimization of oligodendrocyte progenitor cell culture method for enhanced survival. J. Neurosci. Methods 149, 50-56. 


\section{المالخص العربى}

\section{تميز الخلايا الجذعية العصبية من البصيلة الشمية للخلايا ذات التفرعات الشجيرية القليلة}

زينب عبد الفني شومان* . أحمد شوقي عبد المقصود* . سماح السيد الشحات* . هاني السيد مرعي**

*قسم الخلية و الانسجة كلية الطب البيطري- جامعة المنصورة

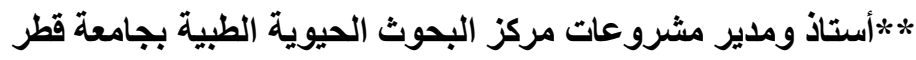

الخلايا الجذعية العصبية من البصيلة الشمية لها القدرة علي التميز للخلايـا الاولية ذات التفرعات الشجيرية

القليلة باضافة بعد المواد المحفزة ؛ هذه الخلايا لها القدرة فيما بعد علي التميز للخلايا الناضجة من نفس النوع و التي لها القدرة علي انتاج غشاء الميالين الذي اذا فقد تسبب في العديد من الامراض. 